Ambrosio - Cubism and the Fourth Dimension

To appear in Interdisciplinary Science Reviews, vol. 41, no. 2-3

Please cite from the published version

\title{
Cubism and the Fourth Dimension
}

\author{
Chiara Ambrosio \\ Department of Science and Technology Studies \\ $\mathrm{UCL}$ \\ c.ambrosio@ucl.ac.uk
}

\begin{abstract}
This article revisits the historiography of Cubism and mathematics, with a particular focus on Pablo Picasso's uses of geometry at the end of the first decade of the twentieth century. In particular, I consider the artistic appropriation of the concept of the fourth dimension, and its pictorial uses as a conduit for a conceptual reformulation of pictorial space. I investigate Picasso's distinctive adoption of this geometric framework in relation to one of his 1909 experiments across painting and photography, and advocate the possibility of drawing novel historiographical lessons from Picasso's work - lessons that bring the historiography of Cubism in a closer dialogue with recent debates in the historiography of science. I conclude with an appeal to consider the continued relevance of this past experiment in art and science when assessing the contemporary drive toward art-science collaborations, and use the case of Cubism and the fourth dimension as a springboard for a critical reflection on the future directions of art-science collaborations.
\end{abstract}

Keywords: Cubism, Fourth Dimension, Art and Science, Interdisciplinarity

\section{Introduction}

"The new painters do not claim to be geometricians any more than painters of the past did. But it is true that geometry is to the plastic arts what grammar is to the art of the writer. Nowadays scientists have gone beyond the three dimensions of Euclidean geometry. Painters have been led quite naturally, and one might say intuitively, to take an interest in the possibilities for measuring space which in the modern artist's studio were simply and collectively referred to as the fourth dimension" (Apollinaire [1913] 2004, 15).

It is with an appeal to the role of geometry in painting that the poet, playwright and art critic Guillaume Apollinaire opens the third chapter of his 1913 book, Les Peintres Cubistes [The Cubist Painters]. A central source in the history of art criticism, Apollinaire's text contains an invitation to connect Cubism with mathematical ideas "which in the artist's studio were simply and collectively referred to as the fourth dimension". In pointing to the well-established trope of geometry as providing a visual language for the plastic arts, Apollinaire here evokes a newly discovered (at least by artists) mathematical concept that captivated the attention of painters especially in the first two decades of the twentieth century. The fact that, by 1913, Apollinaire could refer to the fourth dimension without delving into further qualifications suggests that he expected his audience to be 
Ambrosio - Cubism and the Fourth Dimension

relatively familiar with it - and indeed, as I will show in the course of this article, the historical record suggests that this was very much the case.

That a technical, mathematical notion was appropriated and used by artists at the beginning of the twentieth century is no longer an astonishing discovery, at least for art historians. The past decades have seen the emergence of a lively body of literature offering conjectures on how the concept of the fourth dimension, and the visual sources associated to it, participated in the reformulation of pictorial space that characterised Cubism in particular, as well as a range of subsequent avant-garde movements. ${ }^{1}$ In this article I want to revisit the historiography of Cubism and mathematics and argue for the continuing relevance of the debates it generated. My aim is twofold. On one hand, I want to explore the historiographical lessons and tensions emerging from the scholarly study of the influence of concepts such as the fourth dimension on artistic practice at the beginning of the twentieth century. As will become evident in the course of my discussion, a primary concern for art historians has been to move away from celebratory accounts of Cubism in which the figure of Pablo Picasso occupies centre stage, at the expenses of the "most intellectual" strands of the movement such as the Puteaux Group. While I acknowledge this shift of emphasis as crucial for the development of a new historiography of Cubism, I propose that the role and influence on mathematical ideas on Picasso's own artistic production can be seen as complementary to the study of how later Cubists such as Albert Gleizes and Jean Metzinger appropriated mathematical ideas and turned them into the very philosophy underpinning their pictorial reformulation of space. More specifically, I will propose that geometry, far from reinforcing the rhetoric surrounding Picasso as the unquestioned 'master' of twentieth century painting, should be interpreted as part of a process of re-contextualisation of the early stages of Cubism. I will suggest that this process of recontextualisation can be framed in ways that share important points of contact with historiographical trends emerging in the history of science.

On the other hand, and perhaps at a more theoretical level, my aim is to place the historical connection between Cubism and mathematics in dialogue with the present revival of interest in the relationship between art and science. Apollinaire here is my cue. The quote I used to open my discussion begins with a cautious disclaimer: "The new painters do not claim to be geometricians". Why would Apollinaire deem it important to specify that the appropriation of geometric concepts by artists did not entail a conflation of painting and mathematics? Chapter three of Les Peintres Cubistes does give us a vague indication of what might have motivated Apollinaire's disclaimer: "The new painters", he states only a few lines earlier, "have been roundly criticised for their interest in geometry" (Ibid.). Here I am not particularly interested in an exegetic study of who might have advanced such criticisms. Instead, I want to show that Apollinaire's concerns resonate with tensions and preoccupations that are still very much alive, especially in the rhetoric surrounding contemporary art-science collaborations: what kinds of expectations should be placed on the current demand to foster interdisciplinary interactions between artists and scientists? What is distinctive of the outputs of such interactions, and why should we consider those outputs desirable?

\footnotetext{
${ }^{1}$ This line of inquiry was first explored by the art historian Linda Dalrymple Henderson, whose work I discuss extensively below.
} 
Ambrosio - Cubism and the Fourth Dimension

In revisiting the history and historiography of Cubism and mathematics, I want to suggest that the most productive way to tackle these current questions is with an eye to the past. The conceptual approach I pursue in this article owes a great deal to Andrew Barry and Georgina Born's (2013) recent work on interdisciplinarity, and particularly their critical analysis of 'art-science' - an emergent interdisciplinary field spanning an array of practices at the interface between art, science and technology. Drawing on contemporary experiments, Barry and Born propose that this kind of interdisciplinary collaboration does not - and should not - serve only the instrumental purpose of providing new audiences for science, nor should it be merely construed as a simplified method to illustrate and celebrate scientific achievements. Instead, they propose that the relation between science and the arts is best conceived as a kind of public experiment, "a type of public knowledge...that is in principle unfinished, in process and dialogical, developing through the reflexive relations between participants who are both the subjects and objects of knowledge (ibid. 263, emphasis in the original). The idea of public experiment follows directly from Barry and Born's broader view of interdisciplinarity as the manifestation of a logic of ontology, "an array of efforts to transform the practice of research and training, inside and outside the academy, leading to the generation of novel problems, objects and relations of research, as well as interdisciplinary subjectivities" (ibid., 18).

Barry and Born's claims about the transformative nature of art and science collaborations forms the conceptual background to my investigation of the relations between Cubism and mathematics, and underpins my arguments about the distinctive kind of knowledge emerging from this interaction. In focusing on contemporary case studies, however, Barry and Born run the risk of overplaying the distinctiveness of 'art-science' collaborations as an invention of our time. In what follows, my aim is to investigate whether it may be instead the case that artists and scientists have been involved in the kind of generative, transformative experimentation that Barry and Born identify with a logic of ontology all along. Thus, revisiting the relations between Cubism and mathematics as an episode in the much longer history of art and science can serve the purpose of contextualising current practices and place them in dialogue with a much longer tradition, a tradition where both disciplines have served as each other's critical counterpart in a sustained and still enlightening way.

\section{The Historiography on the Fourth Dimension in Art}

The scholarly literature on the relations between Cubist art and science dates at least as far back as the 1980s. A key source is Stephen Kern's monumental The Culture of Time and Space 18801918 (1983), a sweeping account of how changes in culture (broadly construed, as comprising emerging technologies and the natural and human sciences, as well as literature, philosophy, architecture and the visual and performing arts) created new modes of experiencing and understanding the two fundamental phenomenological categories of space and time. In a central chapter on "The Nature of Space", Kern tentatively suggests that the Cubists' rendering of multiple points of view might have had deeper roots in popular debates around the concept of the 'fourth dimension': "There was a popular interest in the fourth dimension in France at the time", Kern maintains, citing Apollinaire's writings on the subject, "which might have inspired the Cubists" (Kern 
Ambrosio - Cubism and the Fourth Dimension To appear in Interdisciplinary Science Reviews, vol. 41, no. 2-3 Please cite from the published version

[1983] 2003, 145). In drawing this connection, Kern refers to a seminal article by Linda Dalrymple Henderson, "A New Facet of Cubism: 'The Fourth Dimension' and 'Non Euclidean Geometry' Reinterpreted", published in 1971 in The Art Quarterly. The article's main claims appeared in an expanded version in Henderson's 1983 book The Fourth Dimension and Non-Euclidean Geometry in Modern Art, now a standard reference in studies of the relations between modern art and the popularisation of $n$-dimensional geometries in the twentieth century. ${ }^{2}$

Henderson's pioneering work paved the way for a revival of scholarly interest in the historiography of modernism and science, a revival that reached its height in the early 2000s. ${ }^{3}$ The concept of the fourth dimension in painting features in central reference texts in art history, such as Christopher Green's Art in France (2000). "For many of those who found modernity in Cubist art", Green explains, "that modernity was tied up in a quasi-scientific, quasi-philosophical view of the world which....went beyond observation and logic, so that in fact a major attraction of the notion of fourth dimension was its very resistance to representation" (Green 2000, 147). From the perspective of the history of science, Arthur I. Miller's Einstein, Picasso (2001) singles out the figure of Henri Poincaré as the common source for Cubism (via the insurance actuary Maurice Princet, to whom we shall return later) and relativity (in conjunction with Herman Minkowski's fourdimensional representations of space-time). Far from tracing a direct relationship between Cubism and relativity, and in response to the literature that in previous decades had simply assumed such a relationship, ${ }^{5}$ Miller's 'parallel biographies' approach identifies Poincaré as the conceptual common denominator between Einstein and Picasso, the two main protagonists of his story. In doing this, Miller acknowledges Henderson's original efforts to clarify that relativity only had an effect on art at a later stage, and certainly not on Cubist artists in the 1910s. It is now fairly established that the

\footnotetext{
${ }^{2}$ Henderson's book has recently appeared in a new edition with a revised and expanded introduction (Henderson 2013). I refer to the latest edition throughout this article.

${ }^{3}$ Here I only focus on the literature on the fourth dimension. However, a much larger and now wellestablished literature extended the scope of Henderson's original project to broader aspects of the relation between modernism and science. See for example Clarke and Henderson (2002), a collection of essays that examines the shifts and changes in modes of artistic and literary representation between the nineteenth and twentieth century. Parkinson (2008) offers a thorough overview of how Surrealist artists responded to, and adopted, themes and concepts from relativity and quantum physics. Brain (2002, 2008 and 2015) traces the origins of modernism in late nineteenth-century physiological aesthetics and the emergence of recording and graphic technologies. Holton, Galison and Schweber (2008) explore the legacy of Einstein in art and culture. On the front of artistic practice and computer visualisation, Robbin (2006) dissects the legacy of concepts of hyperspace in contemporary computational techniques, while Steingart (2014) explores the legacy of higher dimensions in the contemporary work of Thomas Banchoff.

${ }^{4}$ While the conflation of Cubism and modernism is by no means straightforward, here Green offers an example of how Cubism has been interpreted as the vehicle of a particular conception of modernity. In referring to modernism I will adopt Green's relatively flexible use of the terminology, but I also aim to tone down its most extreme connotations. If Cubism stands out as conveying a particular conception of modernity, it is, in my account, precisely through its capacity to relate in new ways to the nineteenth century. This aspect of my discussion will become clearer in the next section.

${ }^{5}$ Henderson $(2008,2013)$ offers a thorough overview of how the concept of the fourth dimension in painting has been misleadingly interpreted with relativity. She identifies Gideon (1941) and Laporte (1949) as primarily responsible for seeking in Einstein's 1905 special relativity "a means to validate new forms of artistic expression and to argue for their grounding into culture at large" (Henderson 2008, 101). Laporte's line of argumentation has been also questioned by Holton (1996, esp. p. 131) and Miller (2002, 321 note 79).
} 
Ambrosio - Cubism and the Fourth Dimension

reception of relativity on artistic practice should be understood in relation to the popularity and visibility that Einstein obtained after Arthur Eddington's famous 1919 eclipse expedition, which confirmed the prediction of the curvature of light. ${ }^{6}$ This clarification is important because of the far too common association between the concept of the fourth dimension and time, understood primarily as the four-dimensional space-time continuum formulated by Hermann Minkowski's in 1908. Even well established experts on Cubism, Henderson shows, fell into the dangerous trap of implying a direct relationship between Cubism and relativity precisely by interpreting the fourth dimension often invoked by Cubist artists as time. An example of this is Alfred Barr's (1943) influential discussion of Picasso's Cubist paintings, cited by Henderson as typical of the attitude that still occasionally characterises some accounts of the relations between Cubism and relativity: "This introduction of a time element into an art usually considered in terms of two- or three-dimensional space", Barr states, "suggests some relationship to Einstein's theory of relativity in which time is thought of mathematically as a fourth dimension" (Barr 1943, 31; see also Henderson 2013, 13).

What Henderson crucially points out is that the fourth dimension invoked by Cubist artists at the beginning of the twentieth century was a "forgotten spatial fourth dimension" (Henderson 2013,13 ), the roots of which lay in the late nineteenth-century preoccupation with unobservable phenomena, a preoccupation that had a continued impact on at least the first decade of the twentieth century. The context for this concern was the range of discoveries that pointed toward alternative conceptions of matter and space from the late 1890s onward. Along with J.J. Thomson's identification of the electron, Ernest Rutherford's work on radioactivity, Pierre and Marie Curie's isolation of radioactive elements, and more broadly the strong anchoring of physical research in conceptions of the ether, Henderson singles out the discovery of X-Rays by Wilhelm Röntgen as a particularly powerful visual influence on the conceptualisation of alternative spatial dimensions. " $X$ Rays", she claims, "paved the way for the artistic investigation of higher spatial realms in the years before World War I" (Henderson 1988, 326). ${ }^{7}$ It was thus the spatial fourth dimension advocated by Edwin Abbott in Flatland (1884), the elusive but representable fourth dimension that Charles Howard Hinton aspired to visualise and teach in his A new Era of Thought (1888), and especially the highly visual representations of projections of hypersolids that would culminate in Esprit Pascal Jouffret's 1903 Traité Élémentaire de Géométrie á Quatre Dimensions (Elementary Treatise of Geometry in Four Dimensions) which offered artists a well established medium to translate, visually, their efforts to push representation beyond the boundaries of directly observable phenomena. Henderson's account exposes an illuminating paradox in Cubism, and modernism more broadly: that the most subversive aspect of these emerging art movements lay precisely in their conceptual continuity with the very traditions they aimed to reject. Thus, emphasizing the spatial concept of the fourth dimension artists adopted in the early twentieth century is a move of historiographical significance, in that it repositions and re-contextualises figures and movements that have traditionally been the object of a rather uncritical celebration of modernity, especially in the second half of the twentieth century. I shall return to this important point later.

\footnotetext{
${ }^{6}$ See Henderson 2013, appendix A, Henderson 2008, and Miller 2002, esp. p.291, note 154. See also Parkinson (2008).

${ }^{7}$ This line of investigation has been now extended well beyond painting: see for example Beatriz Colomina's work on X-Rays as the guiding metaphor and logic for architectural transparency (Colomina 2009).
} 
Ambrosio - Cubism and the Fourth Dimension

To appear in Interdisciplinary Science Reviews, vol. 41, no. 2-3

Please cite from the published version

\section{The Forgotten, 'Spatial' Fourth Dimension}

How exactly did this spatial concept of the fourth dimension enter the artistic imaginary? The literature on the fourth dimension began gaining public visibility in Paris in the first decade of the twentieth century. Intellectual debates on the subject populated the pages of specialised journals such as the Revue Philosophique and the Revue de Métaphysique et de Morale since at least the late 1880s, where the concept of the fourth dimension was often discussed within the broader context of philosophical and mathematical controversies around the status of geometrical axioms and the possibility of consistent non-Euclidean geometries. This broader aspect of the debate had a much longer history, and it came to an important turn in the 1820s, when Karl Friedrich Gauss advocated explicitly the possibility of geometries alternative to Euclid. The principles of a consistent non-Euclidean geometry were formalised in the late 1820 s by Nikolai Ivanovich Lobachevsky, and by Bernhard Riemann in the late 1850s. What Lobachevsky and Riemann's approach to non-Euclidean geometry had in common was the hypothesis that space might be curved - that it might have constant negative curvature in Lobachevsky's case, positive curvature in Riemann's case. Lobachevsky and Riemann's conceptions of space challenged Euclid's famous fifth 'parallels' postulate, the self-evidence of which had been questioned even by Euclid's early commentators. ${ }^{8}$ Thus, in Lobachevsky's hyperbolic space, straight lines are replaced with arcs of a hyperbole, so that through a point external to a given line there are at least two parallel lines to the given one. In Riemann's spherical geometry, straight lines are replaced with great circles which will all intersect at the poles. Riemann's spherical geometry contained the additional implication that there may be spaces or surfaces where curvature may vary, and this latter implication became particularly appealing to artists such as the Cubists, and later to Marcel Duchamp (Henderson 2013, 103). Variable curvature negated the principle of the indeformability of objects (a principle which was implicit in Euclidean geometry), so that figures moved on a surface with variable curvature would undergo changes in shape and properties. This aspect of non-Euclidean geometry would impact substantially on the rendering of pictorial objects in Cubism.

The emergence of debates around the fourth dimension, and more generally $n$-dimensional geometry is more difficult to trace, as it received a far less systematic treatment. Mathematicians initially considered $n$-dimensional geometry as a particular case of analytical geometry, to which further spatial coordinates could be added. What these approaches offered was an important perceptual challenge: they required the need of visualising one or more dimensions coexisting with the three that govern perception under normal conditions. New terms were coined, such as 'hyperspace' - the space of four or more dimensions - and 'hypersolids', solid figures generated by the motion of polyhedra in a fourth direction, in analogy with the generation of three dimensional solids by plane figures moving perpendicularly to themselves.

\footnotetext{
${ }^{8}$ Euclid's fifth postulate states "That if a straight line falling on two straight lines makes the interior angles of the same side less than two right angles the two lines, if produced indefinitely, meet on that side on which are the angles less than two right angles". I take this formulation from Heath's (1908, vol 1, 155ff) translation of Euclid, whose lengthy critical apparatus on Euclid's fifth postulate traces the history of how commentators questioned its supposed self-evident status since very early on.
} 
Ambrosio - Cubism and the Fourth Dimension

A particularly influential visualisation of hypersolids was in Charles Howard Hinton's (18531907) A New Era of Thought (1888). Trained in Oxford as a mathematician, Hinton had little luck in pursuing an academic career in England and moved first to Japan in 1887, and then to America. He left his manuscript for $A$ New Era of Thought in the hands of Alicia Boole (daughter of the mathematician George Boole) and John Falk, who jointly wrote the book's preface. Hinton conceived A New Era of Thought as an attempt at training his readers to visualise higher dimensions. It did so in a non-mathematical, non-technical language. His motivations were primarily philosophical, and were rooted in a somewhat unconventional reading of Kant. According to Kant, Hinton explains, the intuition of space (or the 'space sense', as Hinton calls it), is fundamental to structure our experience. Neither Kant nor the following philosophical traditions, however, produced a systematic elaboration of how this space sense can be trained and educated. This is puzzling, Hinton notices, as "according to Kant and according to common experience the trained thinker is one in whom the space sense has been well developed" (Hinton 1888, 3). The "true successors of Kant", in this respect, "are the mathematicians Gauss and Lobachevsky", Hinton maintains (ibid., 4), as their works extends the Kantian idea of spatial intuition beyond the limitations of absolute space. In Hinton's own terms: "If our intuition of space is the means by which we apprehend, then it follows that there may be different kinds of intuition of space. Who can tell what the absolute space intuition is? This intuition of space must be coloured, so to speak, by the conditions of the being which uses it" (ibid.). A New Era of Thought sets out to investigate these philosophical claims empirically, through the progressive geometric construction of a system of cubes into a four-dimensional hypercube, or 'tessaract'. 9 "Just as a cube has various plane boundaries", Hinton explains in his chapter on fourdimensional solids, "a tessaract has various cube boundaries" (ibid., 160). A representation of the tessaract in colour would later appear on the frontispiece of his 1904 book, The Fourth Dimension.

Hinton's ideas reached Paris indirectly, via a number of popular sources on the fourth dimension. One of these sources was Esprit Pascal Jouffret's (1837-1904) Traité Élémentaire de Géométrie á Quatre Dimensions (1903), an illustrated treatise that summarised the state of fourdimensional geometry and provided detailed illustrations of four-dimensional polyhedra projected onto a two-dimensional surface. Here Hinton's writings, partly translated and partly cited in the original in English, appear alongside the works of another authoritative source on the subject: Henri Poincaré. In particular, Jouffret's treatise contains references to an 1895 paper entitled "Space and Geometry", originally published in the Revue de Métaphysique et de Morale, where Poincaré discusses an important distinction between geometric space and perceptual space. Geometric space is isotropic, homogeneous and three-dimensional, whereas perceptual space consists of three further components - visual, tactile and motor space - which render it neither continuous nor isotropic, nor reducible to three dimensions. Jouffret singles out the explanation Poincaré gives of the functioning of visual space. We claim that we perceive in three dimensions, but this is a result of the convergence of our eyes and of an effort to accommodate two initially distinct two-dimensional images formed on our retina, Jouffret explains via Poincaré (Jouffret 1903, vi; Poincaré[1895] 1946, 68). From an experimental point of view, this convergence is nothing but an observed regularity, however: nothing prevents us to conceive a state of affairs where these indications remain as

\footnotetext{
${ }^{9}$ In A New Era of Thought Hinton uses the spelling 'tessaract' instead of the currently more common 'tesseract'.
} 
Ambrosio - Cubism and the Fourth Dimension

independent variables rather than in a constant relation. In Poincaré's own words: "A being who should achieve in such a world the education of his senses would no doubt attribute four dimensions to complete visual space" (ibid.).

It was this less systematic, but more vividly illustrated literature on the spatial fourth dimension that captured the attention of artists in the early twentieth century. Both Henderson (2013) and Miller (2001) emphasize the role of Jouffret's treatise as a conduit of fundamental ideas about the fourth dimension among Cubist artists. Yet, where Miller identifies Jouffret's projections of four-dimensional solids as playing a key role in the completion of Picasso's 1907 Les Demoiselles $d^{\prime}$ Avignon, Henderson places their reception later, and associates it primarily with the completion of Picasso's 1910 Portrait of Ambroise Vollard. Both relate the visual input deriving from Jouffret's treatise, as well as the broader circulation of Poincaré's ideas, to the well documented presence in Cubist circles of the insurance actuary Maurice Princet (1875-1971). Princet joined the group gravitating around Picasso in Paris roughly at the same time as his actuary's license examination, in 1906-1907 (Henderson 2013, 171). His presence is consistently recorded in accounts of the early days of Cubism, where he is clearly identified as the person who introduced mathematical concepts to artists - indeed this role earned him the title 'le mathématicien du Cubisme' (Salmon 1955, 187).

Among the most notable documents attesting Princet's presence among artists in Montmartre is a short piece by the writer André Salmon, then particularly close to Picasso. In his regular column "Courier Des Ateliers" (10 May 1910) for the Paris Journal, Salmon announces the imminent publication of a "curious work on aesthetics" by Maurice Princet, "a mathematician... who preoccupies himself especially with artists who disdain perspective. He praises them for no longer trusting the illusionary optics of not long ago and takes them for geometers" (Salmon 1910, 4). ${ }^{10}$ The same year, Jean Metzinger's "Note sur la peinture" published in the October-November issue of the journal Pan explicitly mentioned the names of Princet and Picasso: "Cézanne showed us forms of living in the reality of light, Picasso brings us a material account of their real life in the mind - he lays out a free, mobile perspective from which that ingenious mathematician Maurice Princet has deduced a whole geometry" (Metzinger 1910, 650; Fry 1966, 60). In the following years, Princet's name would feature prominently in Metzinger's writings and would form the basis of the separate identity that the members of the 'Puteaux group ${ }^{11}$ would craft for themselves partly in response to Picasso's Cubism.

In her account of the role of the fourth dimension in twentieth-century painting, Henderson privileges the influence of mathematical ideas introduced by Princet "on the more theoretically oriented Puteaux artists" (Henderson 2013, 171). In doing this, she explicitly plays down the role of Picasso in the appropriation and elaboration of visual sources from mathematics in the early years of Cubism. Her motivation is twofold. First, she observes that the most substantial accounts of Princet's

\footnotetext{
${ }^{10}$ This striking piece of evidence was first located by Lynn Gamwell. See Gamwell 1980, 163. Alas, Princet's book was never published, but he did, eventually, have the opportunity to write some of his ideas in the preface of the catalogue of Robert Delaunay's first solo exhibition at the Galerie Barbazanges in 1912. The full text of Princet's preface is in Antliff and Leighten 2008, pp. 232-34.

${ }^{11}$ The Puteaux group included Metzinger himself along with Albert Gleizes, Robert Delaunay, Juan Gris, and later Fernand Léger and Marcel Duchamp.
} 
Ambrosio - Cubism and the Fourth Dimension

presence amongst Cubist artists are reported by the very founders of the Puteaux group, particularly Albert Gleizes and Jean Metzinger. She shows, for example, that Gleizes and Metzinger drew on Princet's lessons in geometry to combine their interest in the fourth dimension with a broader grounding in debates on non-Euclidean geometries. Their writings contain clear - albeit occasionally imprecise - references to the broader scientific literature on the subject (Henderson 2013, chapter 2). Thus, for example, along with extensive discussions of Poincaré's 'tactile space' - which Gleizes and Metzinger considered far more fruitful for painting than his notion of 'complete visual space' their 1912 essay Du Cubisme explicitly connects the space of Cubism to "certain of Rieman [sic] theorems" (Gleizes and Metzinger, [1912] in Fry 1966, 111; cf also Henderson 2013, 166 and 205211).

Secondly, and perhaps more crucially, Henderson's motivations are historiographical. In emphasizing the reception of mathematical ideas by the members of the Puteaux group, Henderson's aim is to redirect the historiography of art and science in the twentieth century from a celebration of Picasso as the sole mind behind Cubism to a more nuanced understanding of less discussed, and yet more theoretically oriented strands of the movement. In this she is most successful, as evidenced by the literature that at present forms the legacy of her pioneering approach. However, discarding the influence of science on the early beginnings of Cubism might actually have the opposite effect of leaving the interpretation of works such as Les Demoiselles d'Avignon confined within the domain of art alone. Henderson herself partly falls into this trap, when she claims: "Picasso's art was the product of his own artistic genius in its quest for alternatives to the classical figural tradition and to Renaissance perspective space. The sources of Cubism are to be found within art itself, primarily in African sculpture and the paintings of Cézanne" (Henderson 2013, 159; emphasis mine). While I partly agree with the justification she provides for this claim that a straightforward causal relationship between higher-dimensional geometries and the early sources of Cubism is impossible to trace - the danger is that her conclusions might result in restricting even further the scholarship on Picasso, at the same time encouraging the perpetuation of the very rhetoric that her work purports to challenge.

Rather than reopening the much debated controversy of the 'sources' of Les Demoiselles $d^{\prime}$ 'Avignon and the painting's relation with Cubism, ${ }^{12}$ in what follows I will adopt an alternative strategy. Elsewhere, Henderson herself calls for a re-contextualisation in art along the lines that historians of science have adopted for figures such as Einstein (Henderson 2008, 128). Yet, historians of science have not stopped talking about Einstein, nor have they left the sources of relativity confined within science itself: on the contrary, an achievement of the recent historiography of science has been precisely a reconfiguration of Einstein's work within the broader material and social context surrounding it and constraining it. ${ }^{13}$ I claim that similar methodological and historiographical considerations can be applied to key figures in art - Picasso here being a case in point. Showing that Picasso's art was not just "the product of his own artistic genius" is thus a necessary step to challenge the celebratory tones that still accompany several accounts of his artistic

\footnotetext{
${ }^{12}$ For two different - but not necessarily incompatible - accounts of this issue see Miller (2001) on the role of science on Picasso's painting and Green (2001) on the artistic context and influences on the painting.

${ }^{13}$ See, for example, Galison 2003 and Galison, Holton and Schewber 2008.
} 
Ambrosio - Cubism and the Fourth Dimension

production. ${ }^{14}$ Along similar lines, assuming with Henderson that "the sources of Cubism are to be found within art itself" has the effect of rebuilding old fences around art and around the methodologies and domains of competence of history of art - fences that Henderson herself, and the legacy of her work, contributed to dismantle in the first place. It is in the spirit of reintegrating scientific ideas in the wider cultural context surrounding Cubism that I intend to look at one of Picasso's less reproduced and less examined works, in a brief attempt at 're-contextualising' some of his early Cubist experiments.

\section{A Photograph, a Portrait, and the Fourth Dimension}

The photograph in fig. 1 is part of a collection that is very much treasured by historians of art. It captures a group of paintings and sketches completed by Picasso while on a trip to Horta de Ebro during the summer 1909. The photograph was taken by Picasso himself. The summer of 1909 has been repeatedly singled out as a turning point in the consolidation of Cubism. John Golding, for example, states that this was the time in which Picasso "produce[d] the most important paintings of his early Cubist Period" (Golding 1956, 75). Edward Fry argues that at this point Picasso's elaboration of the shifting perspectives of Cézanne converged into a coherent geometric faceting technique (Fry 1981, p. 93). Paul Hayes Tucker (1982) and Anne Baldassari (1997), on the other hand, have pointed out that photography might have played a crucial role in the synthesis of pictorial planes and perspectives that is characteristic of Picasso's mature Cubist style. The summer trip to Horta de Ebro, on which Picasso embarked with his then companion Fernande Olivier, was planned especially to combine painting with photography (Baldassari 1997, 14).

Both Tucker and Baldassari focus on Picasso's use of the camera to record the Spanish landscape, and on the complementarity of such a recording with works such as Houses on the Hill and the Reservoir (1909). Baldassari, on the other hand, briefly considers a group of photographs of the interior of Picasso's studio, including the image in fig. 1, to notice how they "provided a kind of spatio-temporal précis of the work in progress" (ibid. 74). Along similar lines, Miller associates the photographic recording at Horta to Picasso's continued interest in the creative metamorphosis of his works, or "the conceptual transformations in the work itself and in relation to other works" (Miller 2001 138). The primary focus of all the photographs of Picasso's studio is ambiguous, and it is this ambiguity that renders them particularly interesting. It usually consists of two paintings captured photographically side by side, so as to create an intentional visual dissonance. This is usually accomplished by the juxtaposition of two paintings of roughly the same size. In one particular case, Picasso superimposes two different negatives to obtain the synthesis of four paintings into a single

\footnotetext{
${ }^{14}$ A similar line of argumentation has of course been pursued by art historians, but with a special attention to the relations between art, culture and politics without necessarily bringing science in the picture. Green (2000) explicitly invokes the need of a closer investigation of the tensions between movements, individuals and the socio-political context of art in Paris at the turn of the century. In more explicitly polemic tones, T.J. Clark's recent Picasso and Truth (2013) attacks specifically the scholarship on Picasso and denounces "the abominable character of most writings on the artist" (Clark 2013,4). Clark proposes to separate the "wild swings between fawning adulation and false refusal-to-be impressed" (ibid.) that characterises a great deal of biographical works on Picasso from the artworks themselves, and their relationship with the broader cultural and political context surrounding them.
} 
photograph. ${ }^{15}$ The image in fig. 1 , in this respect, is unusual and distinctive in that it collates four completed portraits of different sizes, as well as several sketches pinned on the wall.

I want to concentrate on the smaller portrait on the left side of the photograph, and the drawings just above it. Unlike other paintings captured in the photograph, this image has been very little discussed in the literature - so much so that there is no consistency over its exact title. ${ }^{16}$ John Richardson briefly mentions it as an example of Picasso's 'creative' use of the suffering of his partners for artistic purposes (Richardson 1997, 135). A kidney infection affected Fernande for most of her trip to Horta, and in several of her letters to Gertrude Stein she voices her frustration at Picasso not taking any notice of her condition (Olivier 2001, 241). Richardson qualifies the portrait as one of the most anguished representations of Fernande (Richardson 1997, 133), but in his (rather characteristic) fixation with the details of Picasso's cruel treatment of his lovers, he misses a unique opportunity to look at this image a little more in detail.

[NOTE: I would love you to see this image. It is a great image, and I am aware that the argument I pursue in this section of my article simply makes no sense in the absence of the figure.

Unfortunately, Open Access publishing and copyright law do not seem to agree on this particular case: at present there is no license I can pay to reproduce online (and in perpetuity) a Picasso image protected by copyright. It is a clear case in which the very important cause of Open Access goes precisely against its purported aims, and I can only apologise for this.

You can find a reproduction of the image in the catalogue Picasso and the Camera, curated by John Richardson, New York: Gagosian Gallery, p. 31]

Fig. 1 Pablo Picasso, Femme assise dans I'atelier de Horta, summer 1909. Gelatin silver print. 4 $1 / 4 \times 31 / 4$ inches $/ 10.8 \times 8.3 \mathrm{~cm}$. Private Collection

Picasso's 1909 portrait of Fernande has not been investigated, at least in the literature, in relation to geometry. And yet the composition is geometric through and through, even in a more accentuated form than the larger piece, Seated Woman, which occupies the larger portion of the photograph. Fernande's head is composed of shaded folding planes; her nose is a slightly tilted wedge; her diamond-shaped eyes emerge from the equally geometric spaces of the eye sockets; the sharpness of her cheekbones geometrically separates her face into several distinguished picture planes. Even the mantilla that frames her face is reduced to its essential geometric details, so that all that remains of it is a mere suggestion of its presence marked by the pointed endings of its edge. It

\footnotetext{
${ }^{15}$ A thorough examination of this particular photograph is in Baldassari $(1994,192)$. Miller interprets this image as a visual attempt at "exploring how the fusion of two sets of Cubist images can give rise to a second-order cubist reality" (Miller 2001, 157).

${ }^{16}$ Alfred Stieglitz's publication in Camera Works (see note 16 below) leaves the image untitled. Richardson $(1996,135)$ labels it Fernande in a Mantilla; Baldassari $(1997,80)$ labels it Head of a Woman (Fernande); Miller $(2001,153)$ labels it Head of a Woman in Mantilla (Fernande).
} 
Ambrosio - Cubism and the Fourth Dimension To appear in Interdisciplinary Science Reviews, vol. 41, no. 2-3 Please cite from the published version

is hard to establish a direct connection between this particular portrait of Fernande and the preparatory drawings on the wall above it, but when examined closely they seem to suggest that Picasso worked on the geometric shape of individual compositional elements before merging them together in this or any of the other paintings surrounding Fernande's portrait. It is less hard to see, however, how the conceptual reformulation of spatial relations that characterises this portrait stands out as a pictorial reformulation of geometric ideas that Picasso might have visually borrowed from Jouffret's Traité (Fig. 2).

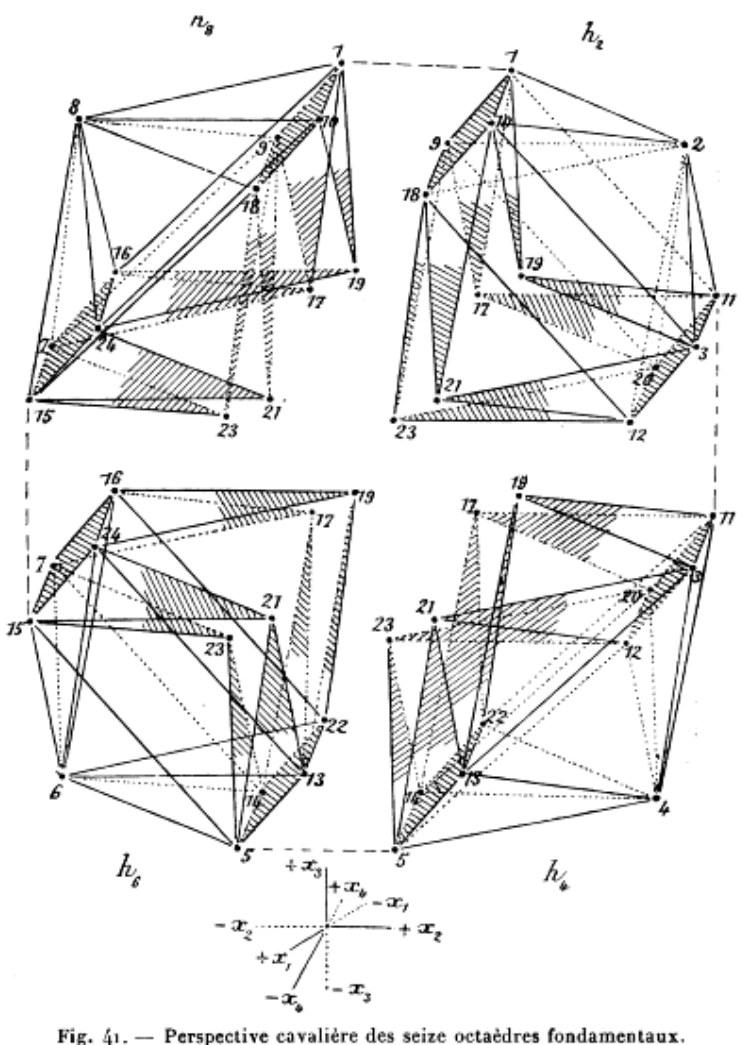

Fig. 2 Esprit Pascal Jouffret, Perspective Cavaliere of sixteen fundamental octahedral, Traité Élémentaire de Géométrie á Quatre Dimensions (1903), p. 153.

Surprisingly, Fernande's portrait has been glaringly overlooked in the literature on Cubism and geometry. ${ }^{17}$ One of the problems might be that the artworks produced at Horta have usually been investigated as central to Cubism, but somehow separately from the cultural (and scientific) context surrounding Picasso's Parisian production. ${ }^{18}$ Yet, even Henderson acknowledges that by

\footnotetext{
${ }^{17}$ The only person who elected this particular work as representative of Picasso's Cubist style was the photographer Alfred Stieglitz, who published a half-tone reproduction of Fernande's portrait in the August 1912 special issue of his journal, Camera Works. See Philippi and Kyeyeser $(1997,644)$. A pioneer of avantgarde art and a crucial intermediary of modernism between Europe and America, Stieglitz had specifically planned the issue around the works of Picasso and Matisse, accompanied by Gertrude Stein's 'prose portraits' of the two artists.

${ }^{18}$ Golding $(1959)$ and Rubin $(1989,1993)$, for example, focus on how the summer of 1909 consolidated the relationship between Picasso and Braque. The two artists had met just after the completion of Picasso's Demoiselles d'Avignon, but it is in the summer 1909 that their styles begin to converge, especially in their
} 
Ambrosio - Cubism and the Fourth Dimension

1909 his relationship with Princet was fairly well consolidated, and his acquaintance with debates around $n$-dimensional geometry fairly established (Henderson 2013,172). Even more striking is the fact that, at least visually, the geometric construction of this particular work presents just the kind of multiple viewpoints and intersecting picture planes that Henderson singles out in Picasso's 1910 Portrait of Ambroise Vollard, explicitly linking this later image to Esprit Jouffret's projections of fourdimensional solids. Her main argument is that, as far as Picasso's case is concerned, the observation that there was a visual affinity between the multi-faceted geometry of Cubism and visual sources such as Jouffret's Traité, came only later, and Cubist painters subsequently adapted to it. "If someone familiar with $n$-dimensional geometry, such as Maurice Princet" Henderson maintains, "had pointed out a visual similarity between Picasso's latest painting and a geometrical diagram such as Jouffret's, it would have seemed to confirm the direction Cubism had taken" (Henderson 2013, 162). But it is not entirely clear from Henderson's discussion why the 'official' starting point of the reception of $n$-dimensional geometry in Cubism should be placed in 1910 rather than earlier on. In the absence of more specific documentation, 'visual affinities' between artistic and scientific imagery is all we have to form a judgment on this issue. The extreme faceting and multiple picture planes that characterise most of the 1909 works at Horta de Ebro, and particularly the portrait of Fernande shown in fig. 1, show that Cubism had taken a geometric direction, along the lines suggested by Princet and possibly inspired by Jouffret, well before the completion of the Portrait of Ambroise Vollard.

Rather than focusing narrowly on issues of dating that might never be settled with absolute certainty, there are two important historiographical and methodological points that I hope my discussion will contribute to elucidate. One is the very place of Picasso within the broader rhetoric of modernism and modernity usually associated to Cubism. One of the reasons for including the photograph in fig.1 in a discussion on Cubism and science is that it exposes a most singular paradox right at the core of a movement traditionally considered at the forefront of modernism. In working simultaneously with an artistic reformulation of $n$-dimensional geometry and photography, Picasso is combining two quintessentially nineteenth-century pursuits. It is the very continuity with this tradition, rather than a sudden rupture with it, that renders Cubism one of the most interesting movements of the twentieth century. Indeed, this has been a concern that art historians have tried to address by distancing Cubism from the nineteenth century as much as possible. An example of this is the response produced by Edward Fry to Paul Hayes Tucker's argument about the pivotal role of photography during the summer of 1909 at Horta de Ebro. Connecting Cubism and photography, Fry argued, would amount to reducing Picasso's works to "a more sophisticated formal and visual development of nineteenth-century positivist attempts to apprehend the data of nature and

appropriation and geometric reformulation of Cézanne's concept of passage (the integration of objects and space and the merging of overlapping planes into one another). The debates around the summer of 1909 are also skewed towards the observation that it was indeed Braque, at least in Golding and Rubin's accounts, the initiator of Cubism. Braque's Cubist landscape paintings of 1909 were completed during his trip to La RocheGuyon, approximately at the same time as Picasso's journey to Horta. This naturally prompted a tendency to read Braque and Picasso's landscapes together; however Braque himself had embraced the role of landscapist explicitly paying tribute to Cézanne at least a year earlier, as exemplified by his paintings of the landscape and houses at L'Estaque. An alternative account, based on emphasizing the differences, rather than the commonalities, in Braque and Picasso's approaches to landscape is in Green (2005). 
Ambrosio - Cubism and the Fourth Dimension

experience" (Fry 1983, 146). The immediate association between photography and positivism, at least in the basic formulation that seemed to concern Fry in the 1980s, has been long dispelled by historians of science. In her 2005 Nature Exposed, for example, Jennifer Tucker shows that the crowd of 'dissenters' to the supposed objective status of scientific photography far outnumbered, even in the context of nineteenth-century positivism, those who claimed to adhere to it. Cubism is the legacy of this particular approach to photography and science more broadly - one in which judgment and conceptualisation are essential to analyse and synthesise data from experience.

My second historiographical point concerns the debate around the 'sources' of Cubism. Following Henderson's line and accepting that the source of Cubism is to be located within Picasso's 'genius' and within art itself seems an easy way to perpetuate the old idea that paying attention to the cultural and socio-political context surrounding art should be construed explicitly in contrast with scientific ideas - as if science were itself separate from politics, social dynamics and the broader cultural context surrounding it. On the other hand, however, trying to draw a straightforward causal connection between Cubism and science will not be unproblematic either. While it would partly answer broader concerns about the lack of integration between disciplinary methodologies, it would do so in science's own terms, somehow suggesting that Cubist art was made better, or at least 'special', by its engagement with mathematical ideas. If this is the case, one would then have to ascertain that Picasso, or the Cubists of the Puteaux group, had a correct understanding of the mathematical notions they adopted in painting, and this is very much open to question. My discussion has hopefully disclosed a different way of looking at this issue, where 'correct understanding' is beyond the point, and where the distinctiveness of Cubism consists precisely in a new type of pictorial knowledge which is not reducible to art or science alone. The assimilation of science (or the suggestion of a 'visual affinity' with it, if we want to follow Henderson's argument) by Cubist artists, including Picasso, generated a transformation of science in Cubist terms, opening new possibilities to conceptualise and experience space.

\section{Art and Science, Then and Now}

In concluding my discussion I want to return briefly to Barry and Born's (2013) work on interdisciplinarity, introduced at the beginning of this article. Specifically, I want to connect the story of Cubism and science to the kind of transformative experimentation described by Barry and Born as a logic of ontology, a set of interdisciplinary practices that lead to the generation of new problems, new objects of inquiry, and new interdisciplinary subjectivities. Far from asserting that Cubism provides us with the same kind of knowledge we would attribute to (or expect from) science, I hope my arguments provided a way of understanding Cubism as a conduit for genuinely novel possibilities to experience and represent space. In this, art served as a form of knowledge in its own right, knowledge that is not in competition with science, but complements it in important critical ways. It is this particular feature of Cubism, in my view, that offers a possible historical counterpart to Barry and Born's account of interdisciplinarity as the manifestation of a logic of ontology.

That artistic practice can play a distinctive critical role seems uncontroversial when it comes to evaluating and understanding the relations between art and politics. What I want to suggest is 
Ambrosio - Cubism and the Fourth Dimension

that the times are now ripe to transfer this fairly established idea to the relations between art and science. In the work Dissensus. On Politics and Aesthetics (2013), the philosopher Jacques Rancière argues that art is first and foremost a means of disclosing ways of "distributing the sensible" (Rancière 2013, 141). Artworks are concrete, historically contingent manifestations of what we are able to experience and conceptualise in a particular cultural and historical context. The critical aim of art, and of aesthetics construed in its broadest sense, is thus for Rancière to disturb the current distribution of the sensible, and propose new criteria for ordering and partitioning what we have access to. Art should make new configurations of experience possible, and it is in this sense that it acts as a way of producing knowledge in its own right.

Rancière's ideas about the critical role of art resonate with Barry and Born's characterisation of interdisciplinarity as a logic of ontology, and I contend that his claims should be transferred from the relations between art and politics to the relations between art and science. They apply especially to the conceptual reformulation of space that Cubist artists developed and opened up, as a pictorial possibility, in response to ideas coming from the field of $n$-dimensional geometry. Far from constituting a threat to the scientific knowledge of the time, the Cubists' appropriation of geometric concepts served to generate new pictorial problems, and with them new modes of conceptualising and experiencing space. Indeed, the distinctive use of geometry in Cubism left a lasting legacy in art and in science (Henderson 2013, pp. 35-90), and is still very much alive in experiments at the boundaries between artistic and scientific visualisation, such as the works of Tony Robbin and Thomas Banchoff. ${ }^{19}$

In this respect, I see Cubism as fitting in what I have elsewhere defined as "artistic visualisation as critique" (Ambrosio 2014, 134ff), an interdisciplinary attitude that aims at carving a distinctive epistemic space and critical role for artistic practitioners in their past and present conversations and controversies with scientists. This particular approach to interdisciplinary research regards the role of art in its specific relation with science as being in many respects very close to the role usually attributed to philosophy of science: that of questioning and critically engaging with assumptions and modes of working that would otherwise be taken for granted by scientific practitioners. This particular critical mission for art adds an important historical dimension to Barry and Born's idea of interdisciplinarity as a logic of ontology, and applies well to the aims and motivations that compelled the Cubists to look at the concept of the fourth dimension to extend their visual quest for an alternative, conceptual reformulation of space. The new artistic knowledge produced through the Cubists' experimentation with science was not taken as the ultimate pronouncement on the subject of space - no artistic experiment would be animated by such an aspiration. It was instead knowledge of a distinctively dialogical and unfinished kind, with a transformative power that still has effects in the present: even the simple use of 'Cubism' as a metaphor continues to evoke powerful associations with a radical redefinition of pictorial space. In looking at Cubist art as an example of interdisciplinarity that presents the characteristics of a logic of ontology, my account of the relations between Cubism and mathematics has thus hopefully suggested the possibility, and desirability, of exploring the continued relevance of a past experiment in art and science that still offers important historiographical and epistemological lessons. In a time

${ }^{19}$ See Robbin (2006). On Banchoff's mathematical work see Steingart (2014). 
Ambrosio - Cubism and the Fourth Dimension To appear in Interdisciplinary Science Reviews, vol. 41, no. 2-3

Please cite from the published version

where 'art-science' is embraced unquestioningly, often more as a fashionable trend than as a mode of knowledge, the story of Cubism and mathematics compels us to think very seriously about the products of interdisciplinary collaborations in relation to the environments, subjectivities and interactions that makes these collaborations possible, fruitful, and sustainable. That an episode in the history of art and science from the past century might offer a template for our contemporary ways of thinking about interdisciplinary collaborations will certainly perplex contemporary scientists, and perhaps even contemporary artists. But if we are committed to interdisciplinarity and the knowledge we demand from interdisciplinary collaborations, perhaps the best way forward is to approach the problem with an eye on the past, and use it to disturb and re-distribute the assumptions we make about the present.

Chiara Ambrosio is a Lecturer in History and Philosophy of Science at the Department of Science and Technology Studies (UCL). Her research focuses on representation across art and science, with a specific focus on nineteenth and twentieth century visual culture. Her published works combine philosophical accounts of representation with historical investigations into particular modes of image-making, such as painting, diagrams and photographs, and the debates around their epistemological status at the turn of the century. The conceptual framework underpinning her research draws substantially on American Pragmatism, especially the philosophy of Charles S. Peirce.

\section{Acknowledgments}

I am grateful to J.V. Field and Frank James for their encouraging and thought-provoking comments on an early draft of this paper. James McKee at the Gagosian Gallery and Pete Woronkowicz at DACS provided prompt help in locating Picasso's photograph of Fernande's portrait and invaluable advice on copyright permission. Niall Le Mage ventured with me on yet another journey through the fourth dimension, asking questions all along. The honesty and sharpness of his criticism added a great deal to the final shape of this piece.

\section{References}

Ambrosio, Chiara, 2014. "Objectivity and Representative Practices across Artistic and Scientific Representation", in Carusi, A. Hoel, A.S., Webmoor, T. and Woolgar, S. Visualisation in the Age of Computerisation. London: Routledge, pp. 118-144.

Antliff, Mark and Leighten, Patricia, 2008. A Cubism Reader, Documents and Criticism, 1906-1914, Chicago: University of Chicago Press.

Apollinaire, Guillaume, [1913] 2004. The Cubist Painters, transl. Peter Reid. Berkeley and Los Angeles: University of California Press.

Baldassari, Anne, 1997. Picasso and Photography: The Dark Mirror. Paris: Flammarion.

Baldassari, Anne, 1994. Picasso Photographie: 1901-1916. Paris: Éditions de la Réunion de Musées Nationaux. 
Ambrosio - Cubism and the Fourth Dimension To appear in Interdisciplinary Science Reviews, vol. 41, no. 2-3

Barr, Alfred, 1943. What is Modern Painting? New York: Museum of Modern Art.

Barry, Andrew and Georgina Born (eds.), 2013. Interdisciplinarity: Reconfigurations from the Natural and Social Sciences. London: Routledge.

Brain, Robert M., 2015. The Pulse of Modernism: Physiological Aesthetics in Fin de Siécle Europe. Washington: University of Washington Press.

Brain, Robert M., 2008. "The Pulse of Modernism: Experimental Physiology and Aesthetic Avantgarde circa 1900". Studies in History and Philosophy of Science, vol. 39, pp. 393-417.

Brain, Robert M., "Representation on the Line: The Graphic Method and the Instruments of Scientific Modernism", in B. Clark and Henderson, L. D. (eds.), From Energy to Information: Representation in Science, Art, and Literature, Stanford: Stanford University Press, 2002, pp. 155-178.

Clark, Bruce and Henderson, Linda D. (eds.), 2002. From Energy to Information: Representation in Science, Art, and Literature, Stanford: Stanford University Press.

Colomina, Beatriz, 2009. "Unclear Vision: Architecture of Surveillance", in M. Bell and J. Kim (eds). Engineering Transparency: the Technical, Visual and Spatial Effects of Glass. New York: Princeton Architectural Press, pp. 78-87.

Fry, Edward F., 1983. "Picasso, Photography and Cubism", Art Bulletin, vol. 65, pp. 145-6.

Fry, Edward F., 1981. Review of Pierre Daix and Joan Rosselet, Picasso: The Cubist Years 1907-1916 (Boston: New York Graphic Society, 1979), in Art Journal , Spring issue, p. 93.

Fry, Edward F. (ed.), 1966. Cubism, New York: McGraw-Hill.

Galison, Peter L. 2003. Einstein's Clocks and Poincaré's Maps. New York: W.W. Norton \&Co. Galison, P., Holton, G and Schweber S. (eds), 2008. Einstein for the $21^{\text {st }}$ Century. Princeton, $\mathrm{Nj}$ : Princeton University Press.

Gamwell, Lynn, 1980. Cubist Criticism. Ann Arbor: UMI Research Press.

Gideon, Sigfried, 1941. Space, Time and Architecture: the Growth of a New Tradition, Cambridge, Mass.: Harvard University Press.

Gleizes, Albert and Metzinger, Jean [1912] “Cubism”, In Edward Fry (ed), 1966. Cubism. New York: McGraw Hill, pp. 105-111.

Green, Christopher, 2005. Picasso, Architecture and Vertigo. New Haven and London: Yale University Press.

Green, Christopher, 2001. Picasso's Les Demoiselles d'Avignon. Cambridge: Cambridge University Press.

Green, Christopher, 2000. Art in France 1900-1940, New Haven: Yale University Press. 
Ambrosio - Cubism and the Fourth Dimension To appear in Interdisciplinary Science Reviews, vol. 41, no. 2-3

Golding, John, 1956. Cubism: a History and Analysis. London: Faber and Faber.

Heath, Thomas L. 1908. The Thirteen Books of Euclid's Elements, translated from the text of Heidelberg with commentary. Cambridge: Cambridge University Press.

Henderson, Linda D., 2013 Non-Euclidean Geometry and the Fourth Dimension in Modern Art. Cambridge, Mass: The MIT Press.

Henderson, Linda D., 2008."Einstein and 20 ${ }^{\text {th }}$-Century Art: A Romance in Many Dimensions", in Galison, P., Holton, G and Schweber S. (eds), 2008. Einstein for the $21^{\text {st }}$ Century. Princeton, $\mathrm{Nj}$ : Princeton University Press, pp. 101-129.

Henderson, Linda D., 1988. "X-Rays and the Quest for Invisible Reality in the Art of Kupka, Duchamp and the Cubists", Art Journal vol. 47, pp. 323-340.

Hinton, Charles H., 1888. A New Era of Thought. London: S. Sonnenschein \& Co.

Holton, Gerald, 1996. Einstein, History and Other Passions. Cambridge, Mass.: Harvard University Press.

Jouffret, Esprit P., 1903. Traité Élémentaire de Géométrie á Quatre Dimensions. Paris: GauthierVillars.

Kern, Stephen [1983] 2003. The Culture of Time and Space 1880-1914. Cambridge, Mass.: Cambridge University Press.

Laporte, Paul, 1949. "Cubism and Science", in The Journal of Aesthetics and Art Criticism, vol. 7, pp. 243-256.

Metzinger, Jean, 1910. "Note sur la Peinture", Pan, Oct-Nov., 649-652. Translated in Edward F. Fry (ed.), Cubism, New York: MCGraw-Hill, 1966.

Miller, Arthur I., 2001. Einstein, Picasso: Space, Time and the Beauty that Causes Havoc. New York: Basic Books.

Olivier, Fernande, 2001. Loving Picasso: The Private Journal of Fernande Olivier, transl. by Christine Baker and Michael Raeburn, foreword and notes by Marilyn McCully; epilogue by John Richardson. New York: henry Abrahams Inc.

Parkinson, Gavin, 2008. Surrealism, Art and Modern Science. New Haven: Yale University Press.

Philippi, Simone, and Keyeser, Ute (eds.), 1997. Camera Works: The Complete Illustrations. London: Taschen.

Poincaré, Henri, 1946. The Foundations of Science / Science and Hypothesis/The Value of Science /Science and Method ; authorized translation by George Bruce Halsted. London: Lancaster Pa: Science Press. 
Ambrosio - Cubism and the Fourth Dimension To appear in Interdisciplinary Science Reviews, vol. 41, no. 2-3 Please cite from the published version

Ranciére, Jacques, 2013. Dissensus. On Politics and Aesthetics. London: Bloomsbury Academic Publishing.

Richardson, John, 1996. A Life of Picasso, vol. II: 1907-1917. London: Random House.

Robbin, Tony, 2006. Shadows of Reality: the Fourth Dimension in Relativity, Cubism and Modern Thought. New Haven: Yale University Press.

Rubin, William, 1989. Picasso and Braque: Pioneering Cubism. Boston, Mass.: Museum of Modern Art. Bulfinch Press/Little Brown \&Co.

Salmon, André, 1955. Souvenirs Sans Fin, Première Époque (1903-1908). Paris: Gallimard.

Salmon, André, 1910. “Courier Des Ateliers”, Paris Journal (10 May), 4.

Steingart, Alma, 2014. "A Four-Dimensional Cinema: Computer Graphics, Higher Dimensions and the Geometrical Imagination", in Carusi, A. Hoel, A.S., Webmoor, T. and Woolgar, S. Visualisation in the Age of Computerisation. London: Routledge, pp. 170-193.

Tucker, Paul Hayes, 1982. "Picasso, Photography and the development of Cubism", The Art Bulletin vol. 64 (2), 288-299. 